\title{
Conversaciones sobre el espacio: primeras aproximaciones a la ciudad de Cúcuta, Colombia, desde sus habitantes ${ }^{1}$
}

\author{
Adriana Pérez Rodríguez*
}

\begin{abstract}
Resumen
El artículo indaga acerca de los procesos de constitución subjetiva y del espacio social en relación con la creación de diferencias de género, clase y raza. Esto ocurre en constante referencia a unas representaciones de feminidad y masculinidad identificadas en Cúcuta, Norte de Santander: los "traquetos", "venezolanos" y "travestis", donde el cuerpo juega un papel central en su reconocimiento. La población con la que se trabajó fue de aproximadamente 20 estudiantes de décimo grado de dos colegios de la ciudad de Cúcuta, el Colegio Santo Ángel y el Colegio San José, en el transcurso del 2014, con la que se elaboró entrevistas grupales. Mi experiencia de vida consignada en el diario de campo fue analizada en esta investigación.
\end{abstract}

Palabras clave: Espacio - diferencia - género - emociones - constitución subjetiva.

\begin{abstract}
The article consists on the research about subjective and social space constitutional processes in relation to the construction of gender, class and race differences. These processes happen in constant references to certain feminine and masculine representations identified in Cúcuta, North de Santander: "traquetos", "Venezuelans" and "travesties", where the body plays a central role in their recognition. The researched population consisted of approximately 20 students from tenth grade of two different schools: the Santo Ángel School and the San José School. I conducted collective interviews during 2014 and my personal experiences were written down in my field diary, also analyzed in this research.
\end{abstract}

Keywords: Space - difference - gender - emotions - subjective constitution.

1 El término, el que será mencionado en el transcurso del texto, hace referencia al legado Merlau-Pontiano, quien concibe el sujeto como inseparable del mundo, ya que este no puede constituirse enajenado de los sujetos: es en su relación que se crea el sentido de espacio. Al constituirse de esta forma, los sujetos dejan de entenderse como objetos que transitan una superficie para ejercer un poder transformador respecto de ella, y por tanto habitarla (Merlau-Ponty, 1993; Citro, 2011).

* Politóloga, Universidad de Reading, Inglaterra. Magíster en Estudios de Género, Universidad Nacional de Colombia. Docente adscrita a la Facultad de Derecho de la Universidad Libre, seccional Cúcuta, Colombia. Directora del Semillero de Investigación en Estudios de Género Rosa Elvira Cely, de la misma institución. 


\section{INTRODUCCIÓN 1}

Doreen Massey (2005:1): "I've been thinking about 'space' for a long time" [he estado pensando en el 'espacio' durante mucho tiempo]. Con esta reflexión personal que podría sonar vaga e incluso trivial, Massey comienza el recorrido de su libro For Space. También muchas y muchos de nosotros hemos pensando acerca del espacio y la constitución de la espacialidad durante el recorrido y quehacer de nuestras trayectorias sociales, en la mayoría de los casos abordándolo de manera indirecta a partir de vivencias y conflictos cotidianos que logran interpelarnos. En mi caso, este artículo es también una manera de aproximarme a este concepto y no podría haber surgido de algo más personal que una molestia acumulada hace aproximadamente ocho años por diversos cambios sociales que he evidenciado en mi espacio más próximo: mi barrio Los Caobos en la ciudad de Cúcuta. Caobos es un pequeño barrio residencial y comercial de la ciudad, reconocido por ser tradicionalmente de sectores sociales medios altos y altos, del que nunca había pensado de manera consciente hasta qué cambios en la estética, gustos y consumos de sus habitantes, altamente reprochables desde mi punto de vista cuando planteé la propuesta de investigación, permearon 'mi espacio' y lograron interpelarme profundamente.

De acuerdo con Boaventura de Sousa Santos (2003), la realidad no es únicamente aquello inmediatamente perceptible por nuestros diferentes sentidos; es, al contrario, un campo de posibilidades y alternativas que no se agotan en la propia existencia perceptiva. De esta manera, el concepto de 'realidad' se constituye como un campo sensible a resignificaciones y ante todo como un campo múltiple, a diferencia de una totalidad homogénea y unidireccional. El objetivo de este artículo será reconstruir aspectos en la relación con nuestra ciudad a partir de narraciones de los y las participantes, junto con mis experiencias consignadas en el diario de campo, que contribuyan a construir espacios sociales multifacéticos. Deseo desbordar las fronteras que demarcan la ciudad, postura tradicional de la geografía regional que aborda al espacio como, en términos de Oviedo Delgado Manhecha (2003: 25): "una porción de la superficie terrestre para luego describir sus características físicas, humanas y culturales, de modo que dicha descripción llegar a reflejar la personalidad de esa porción de tierra denominada región". A partir de nuestros conocimientos situados, planteados de forma dialógica, la definición de ciudad se transforma, posibilitando entenderla no como un contenedor independiente de los fenómenos sociales, sino como un lugar habitado cuyas relaciones reflejan tramas más extensas de complicidades y conflictos, de procesos históricomateriales así como de resignificaciones y potencialidades ocasionales (Lindón, 2009).

Los análisis situados, fundamentales en el desarrollo de conocimientos feministas, nos acercan a la producción de conocimientos de manera incorporada, situados en cuerpos y relaciones específicas. Sandra Harding nos recuerda:

La vida de las mujeres (¡nuestras muchas y diferentes vidas con sus diferentes experiencias!) proveen un punto de inicio para elaborar preguntas críticas no solo acerca de nuestras

1 Este artículo recoge parte de la investigación realizada para la de tesis de maestría: "Feminidades, masculinidades y construcción de la diferencia en Cúcuta, Norte de Santander: miradas cruzadas desde la juventud escolarizada". 
vidas, también sobre la vida de los hombres y, de manera más importante, la relación causal entre ellos y ellas (1987: 55$)^{2}$.

Sus narraciones evidencian una multiplicidad de posiciones desde donde se hace una reconstrucción de la ciudad que se asemeja a una constelación salpicada y multifacética. Nuestra Cúcuta habitada, sus calles, colegios y barrios, se (re)descubre creativamente a partir de nuestras experiencias. De esta forma, sigo los lineamientos propuestos por Donna Haraway (1995: 335), que plantea que los conocimientos feministas parten de "la visión de un cuerpo, siempre un cuerpo complejo, contradictorio, estructurante y estructurado, contra la visión de arriba, de ninguna parte, desde la simpleza".

\section{APROXIMACIONES TEÓRICAS AL ESPACIO Y CONSTRUCCIÓN DEL EXTRAÑO}

Como recuerdan Arango, Bello Ramírez y Ramírez (2013), uno de los debates que han conseguido centralidad y una siempre renovada fortaleza en la disciplina de las ciencias sociales es aquel acerca de la reproducción de las lógicas de dominación y el papel de los sujetos dentro de este marco. Este debate ha sido un componente central para las teorización del concepto del espacio en las orillas de la geografía feminista, la sociología, la fenomenología y la economía política, entre otras. Es importante mencionar que este artículo no pretende abordar la amplitud y complejidad de esos debates acerca de la conceptualización del espacio, sino servirse de propuestas de autoras y autores específicos que procuran complejizar la relación espacio-sujeto-emociones y ver cómo a partir de esta se construye, reconstruye y transforma el universo social que habitamos. Introduciré a Pierre Bourdieu, quien hace un énfasis notorio, mas no excluyente, respecto del carácter estructurado del espacio social; las propuestas de las geógrafas feministas Linda McDowell y Doreen Massey quienes evalúan la fuerza constituyente de las relaciones sociales y sus efectos en el espacio; junto con Olga Sabido Ramos y su conceptualización del extraño.

Pierre Bourdieu es probablemente uno de los sociólogos más estudiados en las ciencias sociales: sus conceptos de habitus, capitales, campo y reproducción han sido aplicados en una amplia variedad de investigaciones. Sus propuestas se ubican en el marco del debate epistemológico entre el objetivismo mecanicista, que pretende que los sujetos responden únicamente a mecanismos coercitivos externos, y el subjetivismo racionalista, que asegura que los sujetos actúan de manera racional y coherente, bajo cálculos deliberados de riesgo-beneficio, para proponer una dialéctica relacional entre ambas posturas (Bourdieu, 1989). Para el autor, el espacio social no es una realidad ajena a los sujetos sino su realidad misma, un campo histórico construido por relaciones antagónicas que se afirman a partir de oposiciones, naturalizadas en estructuras mentales y sistemas de percepción. De acuerdo con el autor, los puntos de vista hacen parte de las estructuras mentales:

Visiones parciales tomadas a partir de un punto (situ) en el espacio social. Y ello sin olvidar que esos puntos de vista determinados también son determinantes: contribuyen en grados

2 Traducción propia. 
diferentes a hacer, deshacer y rehacer el espacio, en la lucha de los puntos de vista, las perspectivas (1994: 241).

Estas visiones construidas por las estructuras objetivas del espacio habitado contribuyen en la reconstitución del espacio, significando para Bourdieu (2012: 241) un doble sentido del concepto: el espacio es una relación estructurada: "en tanto espacio objetivo, estructura de relaciones objetivas que determinan la forma que pueden tomar las interacciones y la representación que de ellas pueden tener aquellos que se encuentran en dicho espacio o estructura", pero también de reacciones prácticas con capacidades restructurantes que se apropian del espacio social, lo reconstruyen y resignifican.

El espacio social, por tanto, nos comprende, pero en ese proceso se vuelve nuestro objeto de conocimiento: lo comprendemos, comprendemos (de manera práctica la mayoría de veces) nuestra posición social y las relaciones de poder que ahí construimos. En ciertos casos lo desaprendemos para reapropiarlo nuevamente desde otras posiciones, que en términos de Bourdieu (1999: 123): "si bien el habitad contribuye a formar el habitus, este hace lo mismo con aquel, a través de los usos sociales, más o menos adecuados, que induce a darle". Como podrá ser observado en la profundización del trabajo de campo, no existen barrios, calles y colegios ajenos a conflictos simbólicos, sino que hay barrios, calles y colegios apropiados y clasificados en "mejores jornadas" contrapuestas a "peores jornadas" dentro de un mismo colegio, barrios de "recursos bajos" con gente "corroncha" contrapuestos a gente "bien" que vive en lugares "normales".

De acuerdo con Bourdieu, el espacio está construido de forma que la arquitectura física refleje las posiciones sociales; la proximidad física de las personas refleja una mayor correspondencia con propiedades sociales y con los capitales, lo que me lleva a preguntar: ¿qué recursos de sentido utilizo para designar a unas personas como extraños amenazantes y a otras como parte "natural" de mi espacio habitado? No considero a todas las personas con las que comparto mi espacio físico ${ }^{3}$ como próximos amenazantes, una empleada de servicio que cohabita en espacios íntimos del hogar puede verse desde la condescendencia o la indiferencia, mientras que los nuevos vecinos son leídos desde el desagrado y amenaza. Como nos recuerdan Lindón y Hiernaux (2012), el asunto del espacio social no se limita únicamente a cómo y por qué es producido, también a cómo los sujetos lo apropian y lo resignifican a partir de interrupciones, cómo articulan estos flujos con sus estructuras mentales y perceptivas y cómo lo van construyendo en su cotidianidad.

De acuerdo con Linda McDowell (2000: 147), el espacio no está definido por coordenadas cartesianas, sino por "la combinación y coincidencia de un conjunto de relaciones socioespaciales". El concepto debe problematizar los aprendizajes geográficos tradicionales, como aquellos impartidos en mis clases escolares de geografía en las que mi conocimiento espacial se construyó aprendiendo a dibujar planos autocontenidos de la geografía nacional y determinados por coordenadas, ajenos a cualquier aspecto de nuestro universo social.

3 Como mi casa, mi barrio, mi colegio por razones relacionadas a conflictos sociales y relaciones de poder que serán expuestas posteriormente. 
Su definición de espacio se complejiza a medida que avanza su libro Género, Identidad y Lugar, por lo que en este trabajo identifico cuatro ejes analíticos para presentar sus ideas y facilitar su comprensión. Un primer eje es el carácter fluido y conflictivo del espacio, definido por prácticas y relaciones sociales de exclusión que se yuxtaponen y determinan los límites entre quienes pertenecen y quienes quedan excluidos, expresando jerarquizaciones y disputas. Estas delimitaciones pueden ser tanto físicas, por medio del levantamiento de muros divisorios, o también simbólicas dentro de un mismo escenario físico compartido. El segundo eje hace énfasis en la cautela en la evaluación de la fluidez del espacio debido a que las relaciones están informadas por estructuras sociales objetivas. Si bien el espacio está constituido a partir de la confluencia de relaciones sociales, estas están informadas a su vez por estructuras relativamente estables que se fijan al espacio de manera duradera, con efectos en los posibles encuentros junto con aquellos que son impensables e improbables. De acuerdo con la geógrafa feminista, en esta tensión entre las continuidades de estructuras estables y las fracturas a nivel de las relaciones sociales, se constituye el espacio social.

En el mencionado libro McDowell (2000) toma como ejemplo la contraposición de juicios otorgados al embarazo adolescente por parte de jóvenes mujeres en el contexto estadounidense de la clase media blanca y del gueto negro empobrecido, para señalar que la conciencia de sí, dicha capacidad reflexiva para dar cuenta de una en el mundo, es construida a partir de nuestra relación con el espacio. Nunca acabada, es un proceso fluido afectado con los cambios de posiciones sociales. El espacio, entonces, influye en las oportunidades materiales de sus habitantes y en la idea que tenemos de nosotras mismas, cómo nos entendemos, cómo evaluamos los cambios, a los y las otras, entre otras variables. Un cuarto y último eje consiste en el carácter paradójico del espacio, porque un mismo escenario físico como las calles, tomando prestado el ejemplo de Nattie Govlubov, puede significar la liberación y el anonimato al tiempo que el miedo y la vulnerabilidad (Golubov, 2007).

La también geógrafa feminista Doreen Massey hace un Ilamado insistente a liberar el espacio de nociones tradicionales de las esferas académicas europeas del siglo XIX que lo definen como una dimensión residual, estática y coherente, para conceptualizarlo desde la apertura y multiplicidad de las relaciones sociales. Estas dos características son fundamentales para su redefinición: la apertura es necesaria para su potencial político de cambios e intervenciones y la multiplicidad permite una simultaneidad de trayectorias y relaciones heterogéneas a diferencia de una única voz e historia (Massey, 2005). El espacio es, por tanto, relacional y político. Para Allen, Massey y Crochrane (1998: 2) debe ser pensado en términos de prácticas y relaciones sociales que se entrecruzan, lo que significa que emerge dentro de estos marcos sociales: "no están 'ahí afuera' esperando ser descubiertos; son construcciones nuestras (y de otros)" ${ }^{\prime 4}$. Las relaciones sociales abren diversas posibilidades donde los antagonismos coexisten con relaciones de cooperación y solidaridad entre agentes y redes sociales plurales, que no necesariamente ostentan una conciencia de resistencia ante un poder opresor.

$4 \quad$ Traducción propia. 
De esta manera, el concepto de espacio es una arena política abierta que viabiliza la coexistencia y multiplicidad de las relaciones "desde abajo". Una cuestión crucial es que, al ser el espacio la constitución de relaciones sociales múltiples, nunca se encuentra acabado, no se puede teorizar como un sistema cerrado sino en constante producción y reconstrucción. Massey enfatiza el poder transformativo de las y los agentes sobre el espacio social, aunque reconoce el carácter estructurado de las relaciones que se encuentran determinadas por posiciones de dominación y subordinación y el acceso inequitativo a privilegios sociales (Massey, 1994).

La creación y negociación de fronteras espaciales se elabora a partir de procesos de diferenciación y alterización. Deseo rescatar el trabajo de Olga Sabido Ramos, toda vez que esclarece los procesos de producción de la diferencia despreciable. Sabido Ramos (2012: 17) reitera que no existen extraños en sí: "no se entiende sin una relación que lo defina; solo se es extraño en relación a otros. No hay extraños en sí, sino extraños para otros según los marcos de pertenencia en disputa". Con un marcado énfasis fenomenológico, para Sabido Ramos las interacciones cara a cara o no focalizadas ${ }^{5}$ son un locus social para la creación de zonas de familiaridad y diferencia, donde nuestros cuerpos se hacen vulnerables a la mirada del otro quien lo significa con su Sentido ${ }^{6}$ y reacciona a su presencia. En estos intercambios, el extraño es lo ajeno, lo incomprensible desde estos marcos de sentido, como señala Sabido Ramos (2012: 134): "el problema del extraño es un problema de Sentido", que nos impulsa a elaborar toda una variedad de artimañas para mantener nuestra distancia frente esta figura a la que reaccionamos con desagrado.

La relación con el extraño construye espacio, configurando divisiones del espacio social y determinando la movilidad. Con este sentir, reconstruimos nuestros espacios desde relaciones de poder, como la subordinación o la negación al extraño del uso del mismo, su visibilidad en este o su existencia misma. Como nos recuerda la autora (Sabido Ramos, 2012: 65): "así, la ordenación del espacio en afuera/adentro, interior/exterior, izquierda/ derecha, cerca/lejos supone -antes que formas físicas de separación espacial, incluyendo las del propio cuerpo- la reproducción de divisiones sociales entre las personas". Existe una reciprocidad entre las formas de clasificación del extraño, las emociones movilizadas y la reconstrucción de fronteras y coordenadas espaciales, que suponen formas específicas de conocimiento con las que damos sentido a la ciudad habitada. Para la autora (2010: 8) aquello significa: "enfáticamente que la sociedad es, ante todo y por encima de todo, una

5 Me remito a Erwin Goffman (2004), quien introduce ambos términos: las interacciones cara a cara ocurren cuando ambos individuos se encuentran en la presencia física del otro y la atención cognitiva recae recíprocamente en las acciones del otro, mientras que las no focalizadas resultan únicamente de la copresencia pero con distintos focos de atención cognitiva, por ejemplo transitar en las calles de los centros urbanos. Para el autor, las interacciones sociales están organizadas por reglas y expectativas de cómo deben desarrollarse y cómo no esperamos que actúen las personas, pero quedan abiertas a la fragilidad de los gestos corporales que pueden delatar otros aspectos del individuo.

6 En la tradición fenomenológica, el Sentido hace referencia a las pautas orientativas e interpretativas de origen social, del cuerpo en el mundo que habita. Para Sabido Ramos (2012: 139): "la capacidad interpretativa de los agentes (o sistemas psíquicos y sociales) para asignar y construir socialmente significados en el mundo que viven" y que acumulamos a lo largo de nuestras trayectorias biográficas. 
actividad corporal. En otras palabras, el cuerpo y las emociones forman parte de la mismísima constitución de la sociedad".

\section{CONVERSACIONES ACERCA DE LA CIUDAD, SUS ESPACIOS Y CUERPOS}

“¿Ustedes qué piensan de la ciudad?". Con este amplio Ilamado comenzó la primera sesión con ambos grupos estudiantiles, quienes rápidamente respondieron de manera también amplia mencionando temas tradicionales como el clima y las cortas distancias, para luego ahondar en lugares de observación puntuales que marcan sus vivencias cotidianas. Sus intervenciones enuncian dos espacios importantes desde los que se relacionan con la ciudad: sus colegios y las calles de sus entornos. Junto con el tema de mi barrio que surge de mi diario de campo, se desdibuja la noción de ciudad como entidad abstracta, ajena al universo social. En mi investigación, la Cúcuta habitada no es una entidad homogénea, ha sido fragmentada, tiene rostros y lugares específicos con los que nos relacionamos; es un espacio resignificado y reimaginado, no una superficie neutra donde ocurren desplazamientos. Se identificaron calles, colegios y barrios desde donde nos situamos para enunciar nuestra relación con la ciudad. Estos son espacios de socialización importantes donde percibimos cuerpos, relaciones y cambios sociales. Donde también somos percibidos.

\subsection{Calles, venezolanos y travestis ${ }^{7}$}

A medida que la ciudad despliega sus calles y avenidas, los y las participantes expresan sensaciones de inseguridad. Esta experiencia está relacionada de forma cercana con los constantes titulares que acaparan medios nacionales, regionales y locales de noticias acerca del anquilosamiento de la ciudad en el fenómeno de la violencia urbana: "Inseguridad reina en el centro de Cúcuta" (Canal TRO, s/f), "Gremios de Cúcuta se quejaron por la inseguridad en la zona de frontera" (El Tiempo, 2015), "En Cúcuta la mayor invasión es la violencia" (Rodríguez Gutiérrez, 2015), entre tantos, los que no escatiman en usar lenguaje metafórico para movilizar miedos y legitimar proyectos que aumentan el pie de fuerza militar en la ciudad.

Juliana Geraldine ${ }^{8}$ : antes había mucha inseguridad, ¿no? Pero no así como está pasando ahorita.

María Fernanda: uno sicociado, mi mamá es así "iguardó todo?" “Pilas, apenas llegue a tal lado repique!" "Avíseme!" "No se siente sola" y uno como que va caminando y siente que alguien lo sigue. Yo soy de esas que nunca cojo por el mismo lado, yo siempre estoy cambiando de ruta. Lo están vigilando y ya saben a qué horas pasa.

Adriana: ¿sienten que los vigilan?

7 Como recuerda Andrea García (2010) la definición de "travestis" se hace comúnmente desde afuera y desde lo peyorativo, no como mecanismo de autorreconocimiento. Para estudiantes del CSJ, esta población fue asociada con fenómenos de criminalidad y violencia urbana, con el tráfico y consumo de sustancias psicoactivas, junto con un mercado sexual. A sus ojos, todos estos factores contribuyen directamente a la sensación de inseguridad y amenaza a su integridad física y emocional.

$8 \quad$ Extracto de la entrevista grupal con estudiantes del CSJ el 9 de abril de 2014. 
Karen: por mi persona yo creo que sí porque ya me robaron por llamada telefónica, me metieron temor de que mi mamá estaba en una estación de policía, que yo tenía que conseguir una factura junto con joyas y llevarlas allá, y pues yo claro ¡qué susto, mi mamá! Entonces recogí lo que me pedían y salí corriendo a entregar todo a donde me dijeron y terminó siendo un robo. Se llevaron todo, la conocida como 30:30 y claro, después el regaño de mi mamá cuando llegó a la casa y se enteró de todo.

Brandon: porque es que, yo no sé, ahora están diciendo que aquí los venezolanos que vienen a robar y eso crea inseguridad. Inclusive hace poquito hubo un violador que viene de Venezuela.

María Fernanda: sí, estuvo por todos lados, y lo más triste es que el muchacho era portador de SIDA. O también como cuando a mi mamá le gusta que tenga el cabello largo pero hubo un punto donde dijo: "córteselo porque cuando usted vaya caminando la rapan y un tijeraso". Con ese cabello hacen las famosas extensiones y las pelucas, y es bonito que uno se corte el pelo y lo done, pero no así.

Karen: sí, a una niña de la cuadra la robaron y le dijeron que le diera el pelo, que se lo iban a quitar, y como ella no quiso la mataron, entonces ahorita están robando mucho.

Bourdieu (1994) define el espacio físico como un aspecto del espacio social, lo que implica que este es también una sede de la coexistencia entre trayectorias en conflicto. Aquello implica que le damos sentido y reflexionamos acerca de nuestras experiencias, dependiendo de nuestro posicionamiento dentro de las estructuras objetivas. Según la profesora Mejía ${ }^{9}$, los barrios de residencia de los estudiantes del CSJ están en su gran mayoría en zonas empobrecidas de la ciudad donde se han agudizado fenómenos de violencia urbana relacionados con el microtráfico y la prostitución. Existe una relación de doble inclusión porque a partir de su posicionamiento subordinado en una estructura económica inequitativa, evidenciado por las condiciones precarias de seguridad en sus barrios, construyen conocimientos prácticos movilizados por emociones fuertes, como el miedo, respecto de cómo habitarlo y cómo llevar su cuerpo.

Mientras las estudiantes expresaron una relación incorporada del miedo urbano femenino ${ }^{10}$ con una mayor vulnerabilidad a ataques físicos, Brandon no explicita de la misma manera la incorporación de la sensación de inseguridad pero sí la relaciona con la presencia de personas como los "venezolanos". El extranjero amenazante ha sido una figura recurrente en distintos proyectos de construcción de sociedades: judíos, musulmanes, gitanos, colombianos, venezolanos, incluyendo poblaciones nacidas dentro del mismo territorio han adquirido la marca de extranjerismo. Esta etiqueta se despliega para evidenciar, como recuerda Sabido

9 Entrevista elaborada a la profesora de ciencias sociales del CSJ, Amanda Mejía, el 10 de abril de 2014.

10 Para Soto Villagrán (2013: 202), el miedo tiene componentes de género específicos, ya que la experiencia de hombres y mujeres en el recorrido de la ciudad es diferenciada, invisibilizada y naturalizada. Dicha experiencia individual se construye dentro de un marco de relaciones desiguales específicas, concluyendo: "en esta perspectiva el espacio es a la vez una construcción social y emocional, que se produce no solo a través de procesos económicos y sociales, sino a través de relaciones de poder presentes en la vida cotidiana, dentro de las cuales se encuentran las relaciones de género". 
Ramos en sus distintas obras, no un sustantivo sino una relación social que contribuye a afianzar sentimientos de mismidad y pertenencia. Paradójicamente, es con la proximidad física de extranjeros e indeseables que los y las participantes crean un sentido de cohesión respecto de Cúcuta; es posible que este haya sido el propósito ulterior cuando discutían álgidamente de lo que "ha dañado" la ciudad, discusión en la que debatían con autoridad y control referente a Cúcuta como relato colectivo vinculante.

En estas discusiones expresaban que las calles están relacionadas con la vulneración física. Son las mujeres quienes manifiestan miedo ante un posible ataque e identifican partes de su cuerpo como un factor que incrementa sus riesgos, mientras que los supuestos migrantes venezolanos, hombres además enfermos y contagiosos, son señalados como las amenazas latentes. Ellos y ellas retomaron el tema del miedo cuando discutíamos del vestuario en la ciudad:

Adriana ${ }^{11}$ : he escuchado de mucha gente que viene de otras ciudades que le choca mucho ver que las mujeres acá utilizan mucho escote y estampados.

María Fernanda: eso es normal.

Juliana Geraldine: eso es normal acá.

Erik: mucha pantera, travesti. Es que yo vivo en la novena, mejor conocida como la avenida de los travestis. O sea usted puede observar tipo 7, de 7 pm a 7 am usted puede observar un negro acuerpado como mujer, vestido de pantera pero es que leopardo transparente, así amarillo [risas]. A veces llegamos tarde de entrenar entonces y la inseguridad, mucha inseguridad porque si vienen los travestis vienen los mariguaneros que les venden la droga al travesti para que el travesti siga siendo así.

Adriana: ¿ustedes asociarían los travestis con inseguridad?

Juliana Geraldine: a uno le da miedo pasar ahí.

Erik: y lo que pasa es que tienen su puñal.

Karen: no, y es que no todos los travestis son iguales, no todos.

Erik: pero los que pasan ahí sí, se venden, la vez pasada llegaba de una rumba cuando me da por voltear pasando la calle estaba pues oscuro y me dio por voltear cuando veo un gamín y ahí, entonces se me quitaron todas las ganas y [shssss] suba corriendo al apartamento.

Brandon: no pues sí, la inseguridad hace que la gente no llegue a lugares, incluso los parques, la gente salía a los parques.

María Fernanda Galvis: era seguro.

Brandon: entonces usted tiene que estar así, pendiente.

11 Extracto de la entrevista grupal con estudiantes del CSJ el 9 de abril de 2014. 
Este extracto expone la estrecha relación cuerpo-espacio-emociones: los y las estudiantes ejercen un poder significador en esta tríada, evidenciando que la constitución del espacio social no es ajena a quienes lo habitan, sino que emerge dentro de esta compleja relación. En su capítulo "Entre los espacios del miedo y los espacios de la violencia", Soto Villagrán (2013) expresa la temporalidad del espacio y los cambios entre horas del día y de la noche; un mismo lugar no es percibido de la misma forma durante todo el transcurso del día. La avenida mencionada por estos jóvenes posee significados fluidos, percibida desde horas de la noche hasta tempranas horas de la mañana como un ambiente inseguro por la presencia de personas asociados con la criminalidad que transitan y trabajan en ella. El diario local, La Opinión, corrobora sus percepciones acerca de esta avenida con titulares como "Piden mayor presencia policial por aumento de la prostitución" (La Opinión, 2014), "No alcanzó a llegar a su casa, en Belisario" (La Opinión, 2014a), "Expedían sustancias psicoactivas en El Páramo" (La Opinión, 2014b), "Regresó la muerte al barrio Chapinero" (La Opinión, 2014c). La modificación de sus prácticas espaciales, como el cambio de rutinas, la reducción de vida social en los espacios públicos y el preferir no frecuentar ciertos lugares, surgieron como respuestas ante el miedo experimentado, haciendo eco de las palabras de Alicia Lindón (2009: 10): "así, concebir al sujeto espacialmente se reconoce que nuestro actuar en el mundo hace y moldea los lugares y al mismo tiempo deja en nosotros la marca de los lugares que habitamos".

En sus relatos, ellos y ellas expresan una sensación de amenaza ante la presencia de estos extraños, individuos peligrosos o enfermos, que muestran su rostro en unas temporalidades y coordenadas espaciales específicas, pero cuya presencia genera una constante sensación de miedo. Este miedo no debe ser entendido solo como una respuesta o una manera de marcar distancias entre los distintos habitantes de la ciudad, es una manera de rehacer sus espacios que moviliza el apoyo a relaciones abiertamente violentas y excluyentes. Fue con este miedo en la boca que ellos y ellas constantemente brindaban su apoyo a un mayor número de pie de fuerza policial o militar para que "ordenaran" los espacios considerados como "ollas criminales" y señalaban barrios otrora caracterizados por "travestis", ahora son "decentes y vivibles" por las operaciones policiales en la movilidad y habitabilidad que vieron el destierro de esta población a otras zonas de la ciudad.

El énfasis dado a aquella experiencia emocional me causó extrañeza porque en mi percepción dicha sensación no ha jugado tal protagonismo. Massey plantea: "necesitamos conceptualizar la noción de espacio como definida por interrelaciones, como la coexistencia simultánea de interrelaciones sociales en todas las escalas espaciales, desde las locales hasta las globales"12 (1994: 263). El énfasis tanto de Massey como de McDowell concerniente a la fluidez del espacio surge al contrastar las intervenciones previas con las elaboradas por estudiantes del CSA:

Adriana $^{13}$ : ¿qué piensan de la ciudad? ¿cómo la describirían?

12 Traducción propia.

13 Extracto de la entrevista grupal con estudiantes del CSA el 9 de abril de 2014. 
José: que es segura.

[Varios exclaman ¡noooo!].

Adriana: por ejemplo, yo ahorita estaba en otro colegio con otros chicos haciendo este mismo grupo y muchos decían que les parece insegura.

José: no es como Bogotá, que en Bogotá hay mucha inseguridad, tiene que andar con las manos en los bolsillos.

Luisa: no tiene nada de diferente eso.

Angie: no porque usted puede ir acá hablando por teléfono y es muy raro. En cambio en Bogotá a usted la ven con un teléfono y de una ve y se lo roban.

Mónica: no pero pues depende de donde vaya.

Andrés: aparte usted acá pues siente más seguridad pues por lo mismo, es más pequeña entonces uno ve más gente entonces se siente más acompañado. En cambio Bogotá es una ciudad más grande, hay más gente pero usted va en una calle y van tres personas y cualquiera de ella va pensando más.

Para el grupo del CSA, las calles se convierten en escenarios fluidos compuestos por experiencias variadas y contradictorias, desde donde se produce una conciencia del yo diferenciada (McDowell, 2000) al no pensarse como potenciales víctimas de ataques contra su integridad física, ni relacionar figuras puntuales con la criminalidad, a diferencia de sus contrapartes en el CSJ. Esta conciencia diferenciada es producto de desigualdades en el acceso a una vida segura, después de todo son estudiantes que residen principalmente en barrios de clases medias y cuyo colegio queda dentro de un sector caracterizado por ostentar capitales económicos, sociales y culturales de la clase alta cucuteña: está construido en un sector residencial de estrato 6 y uno de sus extremos colinda con los campos del golf de un club social de las clases altas, cuyos predios están en proceso de ser utilizados como terreno para construir un nuevo centro comercial que albergará marcas internacionales renombradas "de lujo". Las condiciones de sus espacios físicos coinciden parcialmente ${ }^{14}$ con su posición social en la ciudad, incorporándose en estructuras mentales y de percepción con las que atestiguan la seguridad que les brinda la ciudad. La noción de Cúcuta se alimenta de los vínculos sociales que tejen entre estudiantes, construyendo aspiraciones en torno a ella y nombrando alteridades amenazantes. Su vida cotidiana en la ciudad se instaura a partir de estas mediaciones intersubjetivas.

Ellos y ellas continúan ${ }^{15}$ :

Adriana: por ejemplo, unas chicas con las que yo estaba hablando expresaban que se sentían como más inseguras que los hombres y ellos les decían que eran unas paranoicas, pero ellas seguían insistiendo que así se sentían.

14 Teniendo en cuenta que son estudiantes de sectores medios y medios-altos.

15 Extracto de la entrevista grupal con estudiantes del CSA el 9 de abril de 2014. 
Diana: tiene mucho que ver, mi mamá es una de las que va a salir, “¿con quién? ¿dónde? ¿por qué?" Y yo "mamá, ¿cuál es la preguntadera?" "isí? ¿van y la violan? ¿van y la agarran? ¿van y la secuestran?" [Su expresión facial en ese momento denota fastidio].

José: las mujeres son más vulnerables que los hombres.

Adriana: ¿por qué crees eso?

José: porque a una mujer es más fácil que la violen que a un hombre porque una mujer no tiene tanta fuerza. En cambio un hombre le van a hacer algo va a mandar una patada, en cambio una mujer no puede, no reacciona tan rápido.

Juan Manuel: son más gallinas [risas tímidas de unas estudiantes].

Adriana: ¿las chicas qué opinan?

María Paula: sí el miedo, el miedo que uno le esté pasando eso y que uno se traumatiza. El miedo de no saber uno qué hacer.

Es necesario ser cautelosa de los contrastes tajantes, estos pueden resultar engañosos ya que sus intervenciones reflejan cómo la posición de clase no es el único determinante de nuestra relación con la ciudad. De modo similar a las estudiantes del CSJ, las estudiantes del CSA también expresan ser educadas en el miedo urbano femenino y en la noción de feminidad débil y vulnerable a ataques masculinos, explícitamente sexuales. Las intervenciones en ambos colegios destacan la interiorización del miedo y la vulnerabilidad corporal femenina, implicando que existen puntos de encuentro en la educación de la feminidad dentro de ambos sectores sociales en Cúcuta. El miedo ostenta una dualidad: es individual en tanto se encarna en cada una de ellas, al tiempo que se configura como una realidad colectiva expresada por estudiantes mujeres de dos entornos socioeconómicos diferentes. En sus intervenciones, el miedo tiene un componente específico de género al encontrarse encarnado en el cuerpo femenino, acto que se vio seguido de descalificaciones de sus experiencias emocionales por los hombres del grupo con expresiones como "exageradas", "gallinas" y "no den papaya y listo", entre otras.

No obstante, las estudiantes del CSJ le otorgan rostros y cuerpos específicos a las amenazas en "venezolanos", "enfermos" y "travestis" quienes marcan fuertemente su relación con la ciudad, mientras que las participantes del CSA no elaboraron este proceso, posiblemente al sentir la inseguridad como un fenómeno menos próximo. Corroborando de nuevo un posicionamiento socioeconómico desigual en el acceso a condiciones de vida segura en la ciudad. Esta relación entre emociones y espacio construye género: el cuerpo y conciencia femenina son constituidos a partir de un sentimiento de vulnerabilidad ante la apropiación o violencia masculina, junto con la incapacidad de ejercer violencias físicas y sexuales.

Existen dos aspectos para resaltar: en primera medida, mientras las mujeres de ambos colegios expresan una sensación de vulnerabilidad frente a posibles ataques en espacios públicos, los hombres fueron incapaces de ponerse en su lugar o expresar interés alguno por los motivos que Ilevaron a esa sensación diferenciada. En cambio, fueron rápidos en 
trivializar sus experiencias, señalarlas como responsables por el mal uso o desconocimiento de la ciudad. Como segunda medida, la sensación de seguridad o inseguridad tiene rostros propios: "travestis", "venezolanos", "enfermos", cuya presencia o ausencia alimenta la amenaza o tranquilidad en algunos participantes. Cuando los y las estudiantes del CSA hacen referencia a la seguridad de sus áreas residenciales, es probablemente por una homogenización poblacional y ausencia de estos Otros. Dicha relación espacio-alteridad crea una conciencia de sí, como indica McDowell, que varía desde una tranquilidad del control de sus espacios próximos, junto con la constitución de una imagen homogénea de la ciudad, o la amenaza e incomodidad en el marco de la lucha por el legítimo carácter del espacio frente a unos extraños peligrosos.

Como se explicita en mi siguiente narración, una conciencia de género se comienza a configurar como resultado de las emociones que produce un espacio generizado. Una conciencia que, vale la pena recordar, es diferenciada, debido a que era yo la que, como las estudiantes, me sentía fuera de lugar mientras que muchos hombres descalifican mis vivencias de exageradas.

Mi diario registra ${ }^{16}$ :

Hoy me encontraba en la casa de Meike, entre desahogos emocionales y catarsis de tesis, terminamos reflexionando sobre nuestra relación con el espacio público. Un punto de confluencia fue cómo llegamos al reconocimiento de un cuerpo diferenciado en femenino al sentir emociones como el miedo, la vulnerabilidad, la impotencia y la rabia en diversos espacios públicos o privados. Durante mis últimos años de bachillerato pensaba que algo sucedía conmigo, algo evidentemente negativo porque el problema no era los espacios donde me relacionaba, como calles o conversaciones entre grupos familiares y de 'pares', sino yo. Algo había de malo en mí porque sentía que no pertenecía a estos, que no estaban hechos para mí, me causaban miedo o me intimidaban, mi presencia no era querida ahí.

En muchos casos tuve (todavía tengo) miedo de salir y me excluí, en muchos casos sentía (todavía siento en ciertas ocasiones) vergüenza de mí misma y alteré mi forma de llevar mi cuerpo y relacionarme. Adquiría todo este conocimiento a partir de la piel, este órgano con el que muchas veces sentimos la vulnerabilidad o impotencia que trae consigo ser mujer: el miedo que recorre el cuero cabelludo y atraviesa nuestra espalda como un rayo, los pies que repentinamente se vuelven más pesados impidiéndonos movilidad o los pelitos que de punta avisándonos que algo no anda bien.

Todo esto lleva a desentender las calles y otros espacios exteriores de Cúcuta desde su inmediatez, para revaluarlos como lugares que (re)construyen y naturalizan jerarquías sociales. De acuerdo con Preciado:

Allí donde la arquitectura parece simplemente ponerse al servicio de las necesidades naturales más básicas (dormir, comer, cagar, mear...), sus puertas y ventanas, sus muros y

16 Extracto de mi diario de campo el miércoles 28 de enero de 2015. 
aberturas, regulando el acceso y la mirada, operan silenciosamente como la más discreta y efectiva de las 'tecnologías de género' (2009: 1).

Materialidad no significa inmediatez, al contrario, la gestión de los espacios físicos en las ciudades ha tenido como finalidad la regulación de las experiencias y la normalización de desigualdades y exclusiones. Ha tenido también como efecto el extrañamiento de una misma, proceso en el que me percibía clasificada y habitando una alteridad incómoda que cuestionaba mi desenvolvimiento práctico en el mundo. Esta tribulación era un instrumento de reconocimiento de que repentinamente me encontraba ubicada en una posición que no controlo, ya que como recuerda Sabido Ramos (2012: 163): "el ámbito de la afectividad y particularmente del sentir es un recurso significativo para marcar jerarquías morales y sociales, es decir, así como las palabras clasifican a las cosas y a la gente, también lo hacen las emociones".

Conocimos, de manera no propiamente reflexiva, el régimen heterosexual desde temprana edad; antes de las lecturas feministas y las clases de la Maestría en Estudios de Género, percibíamos por medio de experiencias emocionales la vulnerabilidad, el miedo y la vergüenza de nuestro cuerpo ante la presencia masculina. Por eso cambiábamos (cambiamos) las rutas, no frecuentábamos (frecuentamos) lugares percibidos de dominio masculino y limitábamos (limitamos) nuestra movilidad en el espacio público. La gestión espacial normaliza regímenes heterosexuales y fabrica el género: cuerpos femeninos pensados como vulnerables, apropiables e irracionales y cuerpos masculinos dominantes, razonables y capaces de apropiar otros cuerpos y espacios. Nuestras emociones son fuentes de conocimiento, nuestros aprendizajes corporales y el entendimiento de nuestra posición en el espacio se da muchas veces por medio de ellas. Nuestras emociones y sensaciones también contribuyen a construir espacio, cuando movilizadas por el miedo gestionamos políticas de movilidad que segreguen y excluyan al Otro amenazante. El desprecio ante su proximidad nos impulsa a erigir fronteras simbólicas o físicas que obstaculizan la habitabilidad del espacio o mantener las políticas de movilidad y habitabilidad estables que nos permiten sentir calma en relación con el control del espacio.

Es interesante resaltar que los y las participantes del CSA, a diferencia de su contraparte del CSJ, en ningún momento mencionaron cuerpos "travestis" en su relación con la sensación de inseguridad. Al contrario, esta categoría surge cuando se refieren a los servicios de cuidados corporales. Cuando les pregunté por la presencia de población transgenerista en la ciudad e hice el paralelo con las respuestas mencionadas por participantes del CSJ, las ubicaron dentro de espacios semipúblicos como peluquerías y salones de belleza, ejerciendo trabajos estéticos y del cuidado. Allí son visibles solo para quienes frecuentan esos entornos, a diferencia de las trabajadoras sexuales relacionadas con fenómenos de inseguridad urbana, y expuestas a la vista de los transeúntes que recorren el espacio público:

Adriana $^{17}$ : chicas, por ejemplo a mí me comentaron en el otro colegio que ven muchos transgeneristas en la ciudad, ¿ustedes qué opinan?

17 Extracto de la entrevista grupal únicamente con estudiantes mujeres del CSA el 24 de junio de 2014. 
Daniela: pues no es que se vea mucho.

Mónica: pues no.

Jessica: pues uno lo ve.

Angie: yo sí los veo más.

Daniela: yo, así operados, solo he visto uno no más, pero usted la ve y es una mujer total. Jessica y Mónica: en peluquerías.

Daniela: la peluquería D' Barbie, pues en Barbie es en donde he visto. Pues Barbie es una que usted la ve y aparentemente es una mujer total, Daniela que antes trabajaba ahí también usted la ve y es una mujer total porque le tienen ya los senos operados, la cola y pues Daniela no es que trabaje mucho el gimnasio, es más como que la operación y se mantiene pero igual usted la ve y es una mujer total pero se ve muy poco.

Angie: en el centro se ve mucho porque en el centro son más que todo las peluquerías que por ejemplo ¿si la han escuchado en el comercial LEX? Ahí hay una peluquería en la que todos absolutamente todos son operados.

Daniela: pero los del centro no tienden a estar operados, sino normal.

Adriana: ¿y ustedes lo dirían que les ven mucho?

Daniela: pues la verdad no.

Angie: casi no, pues ellos tienen sus puntos fijos como el Bulevar que hay muchas discotecas de gays, diría prácticamente que en ese sector hay más de ellos, y por el centro o sea ¿sí me entiende? Están ahí "revoloteando".

D' Barbie es una reconocida peluquería y sala de belleza, ubicada en el barrio residencial y comercial Caobos, reconocido en la ciudad por ser de sectores altos y medios altos, cuya oferta de trabajos corporales y estéticos parece encontrarse estrechamente relacionado a las demandas del sector de la población que requiere sus servicios: mujeres blanco-mestizas de clases medias altas y altas. Si bien se reflejan las ideas planteadas por el detallado estudio sociológico realizado por Arango Gaviria (2011), en este momento no se ha llevado a cabo un estudio a profundidad de estos salones, por lo que las conclusiones son rescatadas de conversaciones y observación cotidiana del barrio, sector en el que resido en Cúcuta. Por otro lado, la zona del centro de la ciudad a la que hacen referencia es mayoritariamente industrial, comercial y no residencial, en donde se encuentran establecimientos identificados como peluquerías que, nuevamente rescatando extractos de conversaciones cotidianas, manejan unos precios más bajos y una variedad más limitada de servicios relacionados con las demandas del sector laboral de la zona.

Una similitud entre ambos relatos es la ubicación de "los travestis" dentro de unas coordenadas fijas de la ciudad, siendo visibles únicamente para quienes frecuentan esos espacios. Este ejercicio de clasificación jerarquiza la habitabilidad de Cúcuta, existen unos 
definidores cuya conciencia expresa una libre movilidad y apropiación de los distintos rincones de la ciudad, y surgen unos extraños clasificados desde el desprecio o la indiferencia a quienes les corresponden unos espacios e interacciones fijas; a ellos también se les demanda exiliarse de ese espacio o se espera que se contengan dentro de ellos.

\subsection{Barrios, "traquetos" y el ascenso de los "nuevos ricos"}

McDowell (2000) enfatiza que no conviene dejarse llevar por aquella noción de fluidez espacial, ya que los conocimientos que orientan las relaciones sociales están informados por estructuras de disposiciones duraderas que se "fijan" al espacio y lo constituyen. Si bien la confluencia de relaciones sociales es crucial en la constitución del espacio, como lo ilustran los y las estudiantes de ambos colegios, es preciso recordar que estas están informadas por estructuras sociales objetivas, como la clase, la raza y el género, relativamente estables. Estudiar el espacio implica identificar y profundizar en este tipo de tensiones entre fracturas y continuidades sociales como fuerza constituyente.

Similar a la propuesta de Mariana Heredia (2011) acerca del reconocimiento otorgado a las clases altas emergentes en Buenos Aires, desde 2006 yo pude dar cuenta de cambios en el espacio físico y social de mi barrio, a partir del reconocimiento de nuevos personajes que confrontaban mis disposiciones de clase y género $^{18}$ :

Mi barrio en la ciudad de Cúcuta, que a mi juicio era "sobrio", prontamente fue cambiando, se fue llenando de familias ruidosas que se hacían Ilamar comerciantes. Su estética corporal y sus comportamientos les delataban -ante mis ojos y los de mis pares, amistades del colegio- como los "nuevos ricos" de la zona: hombres utilizando camisas desabotonadas con rosarios en sus cuellos, a quienes tildábamos como "traquetos", y mujeres "fáciles" con intervenciones estéticas evidentes como cirugías plásticas, vistiendo escotes profundos y ropa muy ceñida al cuerpo. Estos nuevos residentes atrajeron más como ellos. Los rostros de nuestro barrio cambiaban a medida que llegaban más "intrusos", mientras familias conocidas migraban huyendo de estos cambios; acto preferible a relacionarse con estas personas de manera tan próxima. Con esta renovación de habitantes, hubo una renovación arquitectónica: el barrio se comercializó, surgieron locales, especialmente bares que ostentaban una estética "traqueta". A estos lugares les teníamos recelo, no solo no entrábamos sino que nos encargábamos de señalar por qué estaban fuera de lugar, por qué no pertenecían al barrio. Aseverábamos que por más solvencia económica que tuvieran, esos "nuevos ricos" no tenían clase, eran "intrusos" en un lugar que no era el suyo.

La doble relación con mi espacio es evidente: ocupo una posición en mi barrio y tomo también una posición frente a este, orientada por mis conocimientos y dominio práctico que me informan cómo se deben ver, comportar y qué gustos deben ostentar las personas que habitan mi lugar de residencia. Cúcuta para mí no era una entidad abstracta, al contrario, estaba reducida a lugares puntuales en los que socializaba y a partir de sus dinámicas podía

18 Extracto de mi diario de campo escrito inicialmente en mayo de 2014. El segundo párrafo se escribió en enero de 2015. 
dar sentido a los acontecimientos que ocurrían en la ciudad. La incursión del narcotráfico en la ciudad cobró importancia para varias de nosotras con la aparición, visibilidad y reconocimiento de estos nuevos personajes que se reapropiaban de nuestros espacios más próximos y cuyos cuerpos, gustos y prácticas expresaban una solvencia económica a la que no estábamos acostumbradas. Les encontrábamos grotescos. Cuando ocurrió este "desfase entre el habitus y el campo", en términos de Bourdieu, entre las expectativas de quienes pertenecen a ese espacio y las nuevas posibilidades ante los "intrusos", comencé a pensar mi barrio de una manera más reflexiva: Caobos no es solo un punto físico en el mapa de la ciudad localizado entre la avenida 0 y la Avenida Libertadores, la calle 20 y la calle 13; es también un espacio de confrontación simbólica por la conservación de un estilo de vida legítimo y la apropiación de signos y prácticas de distinción, similar a la experiencia relatada por los y las estudiantes del CSJ respecto de la jornada de la tarde.

Las distancias sociales son también distancias corporales, están inscritas en los cuerpos con el lenguaje, el gusto, la estética, y en mi caso las he utilizado como recursos de sentido para advertir la distancia social con estos nuevos habitantes de "mi" espacio físico. A mis ojos, las mujeres "fáciles" no ostentaban los atributos necesarios para pertenecer al barrio Caobos, tampoco lo ostentaban las empleadas de servicio y los vigilantes que con sus cuidados garantizaban nuestra existencia. Sin embargo, a estas y estos últimos les veíamos desde la condescendencia o la indiferencia, en muchos casos cosificándoles como parte de nuestro paisaje urbano e invisibilando su existencia en nuestros espacios más íntimos. Al contrario, las mujeres "fáciles" y los "traquetos" eran inmediatamente visibles para nosotras porque pretendían apropiarse del espacio de la misma manera que nosotros y hacerlo suyo.

Estas reflexiones se canalizaban por medio de emociones como el desprecio, el recelo y el resentimiento. Incluso hoy, si bien he procurado mantener un diálogo abierto conmigo misma con la intención de cuestionar mi rechazo, no puedo evitar sentir nostalgia al caminar por sus calles y presenciar cambios que en ese instante parecen incomodarme, incluso irritarme. Dice Bondi, Davidson y Smith (2007: 1): "Claramente, nuestras emociones importan", ellas han sido canales de conocimiento, reconocimiento y desconocimiento de mis espacios. Es mediante este lente que entiendo a Caobos como un barrio saturado de emociones, entre el afecto, el desprecio y la nostalgia. Esperaba que mi barrio, como principal lugar de socialización, fuese un lugar homogéneo construido desde unos parámetros de clase y género exclusivos, pero producto de estas relaciones sociales antagónicas surge un "sentido de lugar paradójico" (Soto Villagrán, 2013) caracterizado por la coexistencia de emociones ambivalentes. Los espacios físicos están saturados de significados, en muchos casos conflictivos, producto de confrontaciones a nivel simbólico.

\section{A MANERA DE CIERRE}

De manera elocuente Rich expresó:

Escribir 'mi cuerpo' me sumerge en la experiencia vivida, en la particularidad: veo cicatrices, desfiguraciones, descoloramientos, daños, pérdidas, así como lo que me agrada (...) Decir 
'el cuerpo' me aleja de lo que me ha dado una perspectiva primaria. Decir 'mi cuerpo' reduce la tentación de hacer lecturas grandilocuentes (1991: 35).

Este artículo comenzó abordando debates a nivel teórico que desde la sociología, la geografía feminista y la geografía de las emociones exponen cómo no existe una fórmula universal para aproximarse al concepto de "el espacio". El énfasis que Bourdieu desarrolla para develar mecanismos imperceptibles de dominación, no excluye la relevancia otorgada por McDowell y Massey a la fluidez de las relaciones sociales y la coexistencia simultánea de historias heterogéneas. Sin embargo, como señalan Bondi, Davidson y Smith (2002: 1): "la geografía, como muchas otras de sus hermanas disciplinarias, ha tenido frecuentes problemas para expresar sus sentimientos" 19 , por lo que se rescata el "giro emocional" con el fin de indagar acerca del poder constitutivo de las emociones en el conocimiento práctico y conciencia respecto de mi posición en el espacio.

En la estructuración de las discusiones con estudiantes de colegio, también yo hice un Ilamado a abordar "el espacio" por medio de una pregunta de carácter amplio y vago, pero los y las estudiantes devolvieron a la "tierra" estos Ilamados grandilocuentes con sus perspectivas encarnadas. Sumergiéndome en sus experiencias y reflexionando a profundidad con las mías, entendí que mi investigación feminista me obligaba a dejar de hablar de "el espacio" y de "Cúcuta" como narrativas omnipresentes para dar centralidad a nuestros lugares de enunciación: las calles, los colegios y barrios con los "travestis", los venezolanos, los estudiantes de la jornada de la tarde del CSJ y los "traquetos" quienes determinan nuestra relación con la ciudad. Estos espacios, nuestros espacios ${ }^{20}$, son mencionados en una relación imbricada y compleja con los cuerpos que los habitan y las emociones que producen, desde el miedo, el afecto, el desprecio y el sentirnos "fuera de lugar".

Este artículo hace un mayor énfasis en la relación cuerpo-emociones-espacio como un "fuera de sí": percibimos y habitamos como si el universo social ocurriera por fuera de nuestras fronteras anatómicas, pero las narraciones e intervenciones comienzan a problematizar cómo en el complejo habitar del espacio también somos percibidas y en ciertos momentos críticos adquirimos una mayor reflexividad acerca de la mirada del otro o la otra sobre nuestros cuerpos. Bourdieu (1994) nos recuerda que el conocimiento práctico es un conocimiento por el cuerpo, la comprensión del espacio inevitablemente atraviesa nuestros cuerpos, los que no son solo los locus de aprendizajes y experiencias emocionales con otros, también de incertidumbres con nosotras mismas, cambios y mediaciones.

19 Traducción propia.

20 Nuestros en un sentido paradójico: son los espacios en que diariamente socializamos, pero en muchos casos, como fue explicitado durante todo el artículo, nosotras los sentimos amenazadores e intimidantes, haciéndonos sentir que no pertenecemos a ellos, inclusive que no son nuestros. 


\section{BIBLIOGRAFÍA}

Allen, J., D. Massey y A. Cochrane (1998): Rethinking the region, Routledge, Londres.

Anderson, K. y S. Smith (2001): Editorial: Emotional geographies, Transactions of the Institute of British Geographers, 26, pp. 7-10.

Arango Gaviria, L.G. (2011): Género, trabajo emocional y corporal en peluquerías y salones de belleza, La Manzana de la Discordia, 6 (1), pp. 9-24.

Arango Gaviria, L.G., J.A. Bello Ramírez y S.A. Ramírez (2013): “Género, belleza y apariencia: la clientela de peluquerías en Bogotá", Revista Nómadas, 38, pp.185-200.

Bondi, L., J. Davidson y M. Smith (2007): Introduction: Geography's 'Emotional Turn', en J. Davidson, L. Bondi y M. Smith (eds.): Emotional geographies, Ashgate, Edimburgo.

Bourdieu, P. (1989): Social space and symbolic power, Sociological Theory, 7 (1), pp.14-25.

(1994): Meditaciones pascalianas, Anagrama, Barcelona.

(1999): La Miseria del Mundo, Ediciones Akal, Madrid.

(2012 [1979]): La Distinción: Criterios y bases sociales del gusto, Taurus, Madrid.

Canal TRO (s/f): "Inseguridad reina en el centro de Cúcuta", disponible en http://www.canaltro.com/ Nuestra-region-Nuestra-television/index.php/actualidad/item/686-inseguridad-reina-en-elcentro-de-c\%C3\%BAcuta.html [consultado el 16 de febrero de 2016].

Citro, S. (2011): La antropología del cuerpo y los cuerpos en-el-mundo: indicios para una genealogía (in)disciplinar, en S. Citro (ed.) (2011): Cuerpos Plurales: antropología de y desde los cuerpos, Editorial Biblos, Buenos Aires.

Delgado Mahecha, O. (2003): Debates sobre el espacio en la geografía contemporánea, Universidad Nacional de Colombia, Bogotá.

De Sousa Santos, B. (2003): Crítica a la razón indolente: Contra el desperdicio de la experiencia, Editorial Desclée de Brouwer S.A., Bilbao.

García Becerra, A. (2010): Tacones, siliconas y hormonas. Teorías feministas y experiencias trans en Bogotá, Tesis de Grado para la Maestría en Estudios de Género, Escuela de Estudios de Género, Facultad de Ciencias Humanas, Universidad Nacional de Colombia.

Goffman, E. (2009 [1959]): La presentación de la persona en la vida cotidiana, Amorrortu Editores, Buenos Aires.

Golubov, N. (2007): Tránsitos por la ciudad: subjetividad, intimidad y espacios públicos, en R. Parrini Roses (ed.): Los contornos del alma, los límites del cuerpo: género, corporalidad y subjetivación, Programa Universitario de Estudios sobre el Género, México D.F.

Haraway, D. (1995): Ciencia, cyborgs y mujeres: la reinvención de la naturaleza, Ediciones Cátedra, Madrid.

Harding, S. (1987): Is there a feminist method?, en S. Harding (ed.): Feminism and methodology, Indiana University Press, Indianapolis.

Heredia, M. (2011): Ricos estructurantes y nuevos ricos en Buenos Aires: Primeras pistas sobre la reproducción y recomposición de las clases altas, Estudios Sociológicos, 29 (58), pp. 61-97.

La Opinión (2014): Piden mayor presencia policial por aumento de prostitución, disponible en http:// www.laopinion.com.co/demo/index.php?option=com_content\&task=view\&id=444396\&ltem $\mathrm{id}=27 \#$. QQOFco5ws-g [consultado el 13 de marzo, 2015]. 
(2014a): No alcanzó a entrar a su casa, en Belisario, disponible en http://www.laopinion.com. co/demo/index.php?option=com_content\&task=view\&id=444634\&ltemid=33\#.VQOFk45ws-g [consultado el 13 de marzo, 2015].

(2014b): Expedían sustancias sicoactivas en el Páramo, disponible en http://www. laopinion.com.co/demo/index.php?option=com_content\&task=view\&id=443794\&ltemid=33\#. VQOGv45ws-g [consultado el 13 de marzo, 2015].

(2014c): Regresó la muerte al barrio chapinero, disponible en http://www.laopinion.com. co/demo/index.php?option=com_content\&task=view\&id=436348\&Itemid=33\#.VQOFy45ws-g [consultado el 13 de marzo, 2015].

Lindón, A. (2009): La construcción socioespacial de la ciudad: el sujeto cuerpo y el sujeto sentimiento, Revista Latinoamericana de Estudios sobre Cuerpos, Emociones y Sociedad, 1 (1), pp. 6-21.

Lindón, A. y D. Hiernaux (2012): "Renovadas intersecciones: la espacialidad de lo imaginario", en A. Lindón y D. Hiernaux (eds.) (2012): Geografías de lo imaginario, Anthropos, México D.F.

Massey, D. (1994): Space, place and gender, University of Minnesota Press, Minneapolis.

McDowell, L. (2000): Género, identidad y lugar: un estudio de las geografías feministas, Ediciones Cátedra, Madrid.

Merlau-Ponty, M. (1993 [1945]): Fenomenología de la percepción, Planeta-Agostini, Buenos Aires.

Sabido Ramos, O. (2010): El 'orden de la interacción' y el 'orden de las disposiciones'. Dos niveles analíticos para el abordaje del ámbito corpóreo-afectivo, Revista Realces, 3, pp. 6-17.

(2012): El cuerpo como recurso de sentido en la producción del extraño: una perspectiva sociológica, Sequitur, Madrid.

Soto Villagrán, P. (2013): Entre los espacios del miedo y los espacios de la violencia: discursos y prácticas sobre la corporalidad y las emociones, en M.A. Aguilar y P. Soto Villagrán (eds.) (2013): Cuerpos, espacios y emociones: aproximaciones desde las ciencias sociales, M.A Porrúa, México.

Rich, A. (1999): Apuntes para una política de la ubicación (1984), en M. Fe: Otramente: Lectura y escritura feministas, Fondo de Cultura Económica, México D.F. 